DOI: $10.20287 /$ doc.d19.ac5

\title{
Terra deu, terra come: a profanação do dispositivo fílmico por meio do cinema documentário
}

\author{
Kamyla Faria Maia*
}

Terra deu terra come (2009, Minas Gerais-Brasil, 88 min.)

Produção e direção: Rodrigo Siqueira

Fotografia: Pierre de Kerchove

\section{Introdução}

Segundo Agamben, o dispositivo faz parte dos mecanismos políticos que têm a "capacidade de capturar, orientar, determinar, interceptar, controlar e assegurar os gestos, as condutas, as opiniões e os discursos" (Agamben, 2009: 13). Antes dele, o termo foi desenvolvido por Foucault em História da sexualidade e pode ser definido como:

[...] um conjunto decididamente heterogêneo que engloba discursos, instituições, organizações arquitetônicas, decisões regulamentares, leis, medidas administrativas, enunciados científicos, proposições filosóficas, morais, filantrópicas. Em suma, o dito e o não dito são os elementos do dispositivo. $\mathrm{O}$ dispositivo é a rede que se pode estabelecer entre estes elementos. (Foucault, 2000:137).

Para Foucault, os dispositivos estão inscritos em uma posição de poder e têm a finalidade de obter determinado efeito, são ferramentas necessárias para distinguir o que é visto como verdadeiro. Por isso, eles são de natureza estratégica e pressupõem "certa manipulação das relações de força, de uma intervenção racional e organizada nestas relações de força, seja para desenvolvê-las em determinada direção, seja para bloqueá-las, para estabilizá-las, utilizá-las" (Foucault, 2000: 138).

Já Deleuze, quando analisa o termo, lembra que o dispositivo, composto por linhas de natureza diferentes, está ligado a três dimensões: o saber, o poder e a produção de modos de subjetivação.

* Mestre. Universidade Federal de Goiás, Faculdade de História, Programa de Pós-Graduação em História. 74605-080, Goiânia, Goiás, Brasil. E-mail: maia. kamyla@gmail.com 
E, no dispositivo, as linhas não delimitam ou envolvem sistemas homogêneos por sua própria conta, como o objeto, o sujeito, a linguagem, etc., mas seguem direções, traçam processos que estão sempre em desequilíbrio, e que ora se aproximam ora se afastam uma das outras. Qualquer linha pode ser quebrada - está sujeita a variações de direção - e pode ser bifurcada, em forma de forquilha - está submetida a derivações. Os objetos visíveis, os enunciados formuláveis, as forças em exercício, os sujeitos numa determinada posição, são como que vectores ou tensores. (Deleuze, 2006: 01).

Dessa maneira, o dispositivo é responsável por processos de subjetivação ou dessubjetivação, ou seja, interferem na forma como os sujeitos se veem, se julgam e se apresentam. Agamben afirma que a subjetivação nasce da relação entre os seres viventes e os dispositivos, já que os dispositivos capturariam os seres viventes dando origem aos sujeitos. Ao fazer essa captura dos viventes, principalmente por meio da captura do desejo dos indivíduos, os dispositivos lhes oferecem a possibilidade de felicidade e de pertencimento a uma comunidade e é esse sentimento que vai garantir a manutenção do funcionamento social. O sujeito criado nesse processo funciona como engrenagem da máquina e servirá ao intuito principal que é a permanência do funcionamento do dispositivo.

A forma de funcionamento do dispositivo retira as esferas sociais e políticas do uso comum e transforma essas esferas em algo inacessível para a maior parte dos indivíduos, já que apenas os especialistas ou técnicos podem opinar e decidir. Dessa maneira, as pessoas não estariam preparadas para decidir sobre os objetivos, funcionamento, metas e processos das instituições e assim permaneceriam excluídos de qualquer mudança. Para retirar tais instituições do âmbito do inacessível e colocá-las ao alcance das decisões de todos os implicados, Agamben afirma que é preciso recorrer à profanação (2007).

Profanar seria restituir as esferas de poder ao uso comum e, sobretudo, permitir aos indivíduos usá-las das mais diferentes maneiras. Profanação seria uma tentativa de desconsiderar a separação entre o sagrado e o profano, servindo como um anti-dispositivo. Ele aponta também uma relação íntima entre os termos "usar" e "profanar", já que a profanação seria uma operação que desativa os dispositivos do poder e devolve ao uso comum os espaços que o capitalismo, em suas esferas econômica ou jurídica, havia confiscado.

\section{O dispositivo fílmico: legitimação do ato de ver imagens}

O cinema é um dispositivo capaz de interferir nos processos de subjetivação. Quando estamos no cinema, nosso corpo permanece imóvel e nossos olhos continuam a se mover e procurar significados. Para Aumont o cinema seria um dos dois grandes dispositivos de imagem e estaria "baseado nas ima- 
gens projetadas de tamanho variável, mas frequentemente muito grande, vistas ao mesmo tempo por determinado número de espectadores, em um lugar especialmente destinado a essa apresentação" (Aumont, 1993:176). Esses mecanismos seriam responsáveis por legitimar o ato de ver imagens em uma relação determinada por "meios e técnicas de produção de imagens, seu modo de circulação e eventualmente de reprodução, os lugares onde elas estão acessíveis e os suportes que servem para difundi-las" (Aumont, 1993:135).

Compartilhando do mesmo entendimento, Dinara Guimarães classifica o cinema como "vazio iluminado", pois assim como a luz do projetor ilumina a sala, o cinema é capaz de iluminar parcialmente o vazio que nos constitui numa relação direta com a perspectiva da morte, o vazio de toda a significação que se oculta no cerne da produção de sentido. A autora acredita que o dispositivo é um "diálogo com a ausência, o indizível, o para além do não-dito", como uma "busca continuada de uma origem que recua e ao mesmo tempo está sempre presente" como traço, resto. (Guimarães, 1993:11) Ou, de outra maneira, ele é capaz de atingir não apenas nosso olhar, mas também nosso espírito, como "os fantasmas: o que volta sempre, o que assombra" (Aumont, 2004:145).

Avançando mais na análise do cinema enquanto dispositivo chegamos ao conceito de scinestesia, uma síntese entre as noções de sinestesia e cinestesia desenvolvida pelo pesquisador Marcio Pizarro Noronha, por meio do qual a tela de projeção é percebida como "um espaço geográfico habitável", uma superfície que multiplica os trajetos do olhar, num jogo entre "situar-se e ver" (Noronha, 2007: 58). O olhar não deve ser visto apenas como uma atitude ativa do espectador em relação ao filme. Em direção contrária, a obra cinematográfica volta sobre o espectador como olhar. O filme faz com que nos voltemos sobre nós mesmos, em um processo reflexivo, principalmente no cinema documentário.

Dessa forma, o cinema nos objetifica no momento em que toma a direção contrária e nos olha. Didi-Huberman, por meio do estudo das imagens, do cinema e da psicanálise lacaniana, nos mostra não apenas o que vemos nos filmes, mas o que volta para nós como olhar, "o que vemos se abre, nos racha ao meio e nos olha", torna-se o "necessário instrumento de sua capacidade de existir, entre a ausência e a presa, entre o impulso e a surpresa" (Didi-Huberman, 1998: 79). Esse fascínio por imagens, mesmo aquelas que podemos definir como naturais e que são, muitas vezes, banais em conteúdo e sem grande apelo estético, é um dos atrativos do cinema documentário. Fascínio exercido sobre o espectador, consumidor de imagens não-ficcionais; sejam elas de reality shows, reportagens jornalísticas ou documentários. 
No entanto, a atração por imagens captadas diretamente da realidade também recai sobre os realizadores. Isso é perceptível desde o momento inicial do trabalho, no ato de optar por esse gênero em detrimento da ficção. A opção corajosa, em grande medida, de escolher criar uma narrativa por meio de um documentário - considerado de segunda categoria, uma antessala da ficção mostra o poder enigmático do real. Nessa medida, os processos de subjetivação não recaem apenas sobre os espectadores, mas também sobre os realizadores que, da mesma forma, são atingidos pelo poder do dispositivo e, ainda mais adiante, sobre a personagem que tem sua vida representada em um documentário. Todos esses sujeitos são impelidos a voltar-se sobre si mesmos, a refletir sobre suas realidades.

Como uma das tentativas de representar o real, o documentário tem que lidar com um campo rico e controverso: o da memória. Essa pode ser verbalizada e transmitida de diferentes formas pelo sujeito que realiza a busca consciente por suas lembranças ou pelo sujeito que vai em busca das memórias de alguém. Essa verbalização compõe uma narrativa muito próxima às narrativas de ficção, já que ambas utilizam as mediações imaginárias na refiguração do tempo. São momentos nos quais ocorre um encontro entre vida íntima do indivíduo e sua inscrição numa história social e cultural.

As narrativas biográficas são constantemente afetadas pela interpretação do sujeito ou de quem organiza o discurso. Este interlocutor não está passivo dentro do processo dialógico, pois também participa da criação de conhecimento. Narrativas como esta lidam com uma identidade inventada e reinventada, "configurações intencionais que, muitas vezes, ajustam o passado conforme as necessidades do momento" (Galle, 2006: 74). Por isso, como lembra Teresa Maria Malatian ao citar Peter Gay, é preciso tomar cuidado com as escritas de si, pois suas táticas evasivas e jogos de exposição e proteção, mais ocultam do que revelam (2008: 24).

Em decorrência desta constatação é necessário pensar no trabalho do investigador que faz o trajeto de buscar as memórias e também na noção de prova, principalmente aquela trazida pelo pesquisador italiano Carlo Ginzburg. É preciso lembrar que o passado não pode ser reconstruído em sua totalidade e que para chegar a um relato autêntico é preciso rever indícios e testemunhos numa busca por "pensar e representar a realidade, com todos os equívocos e ambiguidades que isso comporta" (Lima, 2007: 111).

As obras não ficcionais, entendidas como um campo propício para a criação de narrativas biográficas, devem ser analisadas sob estes mesmos conceitos. O cineasta invade a vida das personagens tanto para deixar que elas falem sobre si e recriem sua experiência, quanto para recriar a si mesmo a 
partir da história delas, para viver a realidade que elas vivem. Desta forma, o filme se transforma em um testemunho de vida e assim nos leva a conhecer o mundo histórico dos indivíduos. Como define Eliseu Souza (2008: 37) tais documentários podem ser percebidos como "modos de narração constituídos de discursos da memória a partir da centralidade do sujeito que narra".

No entanto, o dispositivo fílmico traz um diferencial à construção de narrativas biográficas, já que, diferente de um relato escrito, estas obras nos possibilitam ver a imagem da personagem biografada. Deparamo-nos com o sujeito em seu todo por meio da imagem em movimento. Nas obras documentais temos a possibilidade de ver suas expressões faciais no momento em que relatam suas lembranças, seus movimentos corporais, suas hesitações, enfim, as emoções que cada momento do testemunho traz à tona para os biografados.

Para analisar um documentário é preciso levar em conta as reações do biografado frente ao aparato cinematográfico, a sua relação com o realizador e as intervenções deste último sujeito na construção da obra. A forma de abordagem e angulação dos filmes podem interferir de forma significativa na maneira como as histórias de vida são relatadas. O documentarista, neste caso, é o observador corporalmente situado no mundo e auxiliado por um dos mecanismos de maior penetração, a câmera filmadora, que produz sentido por sua posição "constitui, em toda a construção perspectiva, um poderoso mecanismo gerador de sentido" (Frayze-Pereira, 2005: 110-113).

\section{A profanação no cinema documentário: Terra deu, terra come (2010)}

O filme Terra deu, terra come, do estreante Rodrigo Siqueira, pode ser considerado uma profanação do dispositivo fílmico, já que ele é desvirtuado de seu caráter burocrático do gênero e expande as fronteiras do conceito de documentário. A fabulação - que vai ao encontro do conceito de cinema documental, sempre ligado com uma ideia comprobatória - aponta que é preciso fazer um novo uso dos meios audiovisuais para tratar de histórias reais, que é preciso brincar, fabular o real. Da mesma forma, é preciso oferecer novos mecanismos para que os seres retratados sejam mostrados em sua plenitude.

A obra conta a história de Pedro de Almeida, ou Pedro de Alexina, garimpeiro de 81 anos de idade que vive com sua família na remota comunidade quilombola Quartel do Indaiá, no distrito de Diamantina, Minas Gerais. Ele é o último cantador de vissungos, os cantos fúnebres em dialeto africano banguela entoados durante o transporte dos corpos para o enterro e que foram trazidos pelos negros escravizados, principalmente aqueles vindos de Angola. O mote principal da obra é mostrar o velório, o cortejo fúnebre e o enterro de João Batista, que morreu aos 120 anos, segundo Pedro de Alexina, o qual atua 
como um mestre de cerimônias do evento. O rito funerário é permeado por vários momentos em que Seu Pedro, familiares e conhecidos recontam memórias familiares e do garimpo em histórias carregadas de poesia e significados metafísicos que nos põem em dúvida o tempo inteiro, principalmente aquelas contadas pela personagem central.

Na parte inicial do filme ouvimos apenas uma voz que parece ser de um idoso, provavelmente do interior de Minas Gerais, muitas vezes de difícil entendimento. Ele fala sobre como Cristo criou a Morte e como ela agiria. Na tela preta, apenas a legenda do que ele diz. Na sequência, somos apresentados - por imagens e letreiros - ao espaço no qual a narrativa vai se desenrolar, o Quartel de Indaiá, São João da Chapada, Minas Gerais. Depois de alguns segundos a voz do idoso retorna, dessa vez sobre a imagem de uma bananeira, filmada de cima para baixo. Ele diz: "Ele está inchando. Vamos ver até amanhã, hein. Ele está inchando. Isso é coração. Coração". Uma mulher pergunta: “Já esfriou?" E ele responde: "Não, está quente.” Ela pede: “Deixa eu ver." E os dois reiteram: "Tá quente!" Para finalizar, o senhor conclui: "O homem escutava, hein diacho. Acha que tá morto e não tá, né. Aí, ele tá quente."

Entendemos que alguém morreu recentemente, pois ainda está quente, e que o filme vai tratar da morte desta personagem ainda desconhecida. Nos minutos seguintes, mais rezas sob imagens de contextualização de uma casa modesta e, finalmente, sabemos que o morto é João Batista. Uma câmera situada dentro dessa casa acompanha o idoso que busca um pano para cobrir o morto. No local, homens jovens, mulheres e crianças, todas negras. Finalmente vemos o corpo, colocado em frente à entrada da casa e coberto por um pano branco. Seu Pedro, o idoso, fala da morte de João para o cineasta. Rodrigo é convocado por Seu Pedro a tocar o cadáver para sentir que ele está morno; o realizador aparece no plano ao tocar o defunto. Seu Pedro corre para buscar pinga para dar ao morto do qual não conhecemos a fisionomia. "Ele era muito pinguço, moço. Se não der ele não acaba, não.”

Seu Pedro diz que agora que está tudo encaminhado é preciso esperar pelo outro dia, para o enterro. Mas lembra que é preciso ficar de olho no morto, pois ele poderia ter contrato com o "Outro" e, nesse caso, seria uma perda de tempo preparar o corpo, pois ele iria sumir antes de ser enterrado. Rodrigo entra em cena novamente indagando sobre o assunto. Seu Pedro chama o cineasta para arrumar a janta para o pessoal e Rodrigo corta a filmagem com uma palma. Finalmente os letreiros iniciais com o nome do filme.

Pelas cenas finais, acreditamos estar assistindo à filmagem de um velório comum, real. Parece-nos que o cineasta, cuja presença é explícita, estaria naquela comunidade quilombola para nos mostrar os costumes preservados pelos 
moradores e o ritual que antecederia o enterro de uma pessoa que acabara de falecer. E estaria no local também para retratar a vida de Seu Pedro. Ao longo do filme conhecemos sua história, ele é um garimpeiro, descendente dos negros escravizados que fugiram para o Quilombo de Indaiá, casado com Dona Lúcia, pai de catorze filhos, que teria ficado rico e perdido todo seu dinheiro por não saber "empregar" o que ganhou e também assassino do genro abusivo. Mas o que se apresenta ao longo do desenrolar do filme acaba por nos fazer suspeitar de tudo o que se passa na tela, pois não existe uma barreira nítida entre o que é fabulação, o que é imaginação e o que é memória. É real ou ficção? As personagens estão relatando o que realmente ocorreu ou estão recriando em cima da própria realidade?

Isso não é exclusivamente uma decisão estilística do cineasta, mas sim uma característica da própria comunidade representada, na qual o místico se mistura com o real. Prova disso é a sequência que vem depois da abertura do filme. O comerciante Seu Pedrin, que parece não conhecer um equipamento cinematográfico, afirma que os integrantes da equipe de filmagem são feiticeiros e que teriam parte com o capeta. Nessa sociedade é racionalmente possível ter parte com entidades espirituais, fazer feitiço ou melhor, ser "sabido". Outras provas são os momentos em que Seu Pedro coloca uma máscara e representa um homem que quer proteger seu tesouro enterrado no quintal da casa. Quem é esse homem, uma personagem criada pelo idoso ou o espírito do morto, cuja "parte" com o "Outro" permite que ele seja "invocado" e retorne no corpo de Pedro para proteger seu maior tesouro?

Até mesmo o que parecia ser um enterro convencional na região ao final se mostra outra das fabulações de Pedro e do cineasta. O corpo é transportado por dois homens em uma rede amarrada a um galho de madeira. Outros homens, mulheres e crianças acompanham o cortejo. Seu Pedro entoa os vissungos e comanda o cortejo. Quando chegam ao local em que João Batista seria enterrado e o corpo é descoberto o que vemos é um caule de bananeira. Em sua ponta a máscara que Seu Pedro usou anteriormente. O idoso finaliza o enterro jogando pinga no "morto" e acendendo um charuto. O cineasta então pergunta em que situação é necessário enterrar a bananeira e o idoso responde que é quando a pessoa que morreu tinha parte inteira com o "Outro" e por isso, tem o cadáver roubado pela entidade. Ele relata também um caso em que isso ocorreu. Então, Seu João Batista morreu, mas como tinha parte com o capeta o corpo foi roubado, sendo necessário enterrar o caule de bananeira?

O que se segue nos responde, em parte, a pergunta acima e nos mostra que não é possível delimitar o que é real, o que ocorreu de fato, como se espera em um filme não ficcional. Durante a fala de Seu Pedro sobre o "causo" do enterro 
da bananeira vemos as imagens dele e de outro homem cortando a planta no quintal e colocando o caule em frente à casa. Essa sequência continua, agora com o áudio original, em que novamente ouvimos a conversa relatada no início deste texto, em que Seu Pedro e Dona Lúcia discutem sobre a temperatura do morto. Entendemos que desde o início o corpo que estava sendo preparado para o enterro era na verdade a bananeira. Não havia morto, não havia velório nem enterro, tudo era apenas uma fabulação, tão bem construída por Seu Pedro que nos sentimos enganados ao seu final.

Nos letreiros que encerram o filme ficamos sabendo que Rodrigo foi à região para resgatar a memória da passagem africana pelo distrito diamantino e que depois de chegar lá propôs que Pedro representasse um velório e um enterro "para instigar sua memória e garimpar lembranças". Segundo o cineasta foi possível "apurar muitas histórias e alguns tesouros. Mas Pedro fez questão de enterrá-los sob uma ambiguidade que transita entre a verdade, a memória e a fantasia". Pedro é o mestre de cerimônias não só do cortejo fúnebre, mas de toda a obra, e nos conduz por um mundo desconhecido e místico. Para se despedir, ele aparece novamente com a máscara, encarnando o homem que protege seu tesouro. O homem que protege antigas tradições. Olha para a câmera e se vai.

Memória, realidade e fantasia se misturam em um nível raro dentro do documentarismo brasileiro. O primeiro ponto desta obra que suscita discussões é a atuação de Pedro e seus familiares frente à câmera, que, a partir de uma mise-en-scène instigante, nos fazem perder a noção do que é real e do que é imaginário, na qual documentário e ficção não se distinguem. Não é possível saber até que ponto Seu Pedro e os familiares representam em frente à câmera ou apenas dão vazão a pensamentos e emoções sinceras. O momento crucial desta confusão é quando o idoso coloca a máscara e começa a interpretar uma personagem que está defendendo seu tesouro. A maquinação do enterro, que ao final se mostra uma grande trapaça, também embaça a fronteira entre o real e a ficção.

O documentário pode ser entendido como um marco do cinema não ficcional nacional, pois esse gênero que se percebe como intimamente ancorado na realidade, se deixa seduzir pela ficcionalização do real e deturpa o método clássico, visto em filmes como $O$ velho. Segundo Lins Terra deu, terra come, "perturba a percepção do espectador em relação ao tema e faz com que a percepção da obra esteja muito mais no sensório do que no campo intelectual" (Lins, 2008: 81).

Nessa obra também está presente a discussão a respeito do fazer documental, já que em vários momentos o aparato cinematográfico e o caráter de 
construção de discurso ficam em evidência, como no momento em que uma das personagens vê pela primeira vez uma câmera de filmagem, a qual chama de feitiço. Da mesma forma, o cineasta não se esconde durante as filmagens, em uma clara referência ao trabalho de Eduardo Coutinho e a relação dele com a personagem central ganha relevância, dando origem a momentos inusitados.

Por outro lado, a atuação de Seu Pedro, enquanto criador do filme é marcante. Ela é destacada no letreiro final e é lembrada também nos créditos do filme, no qual Seu Pedro aparece como colaborador de direção. Ele não pegou a câmera em nenhum momento, e muito provavelmente não teve qualquer controle sobre a forma como o material filmado foi editado, mas a maneira como decidiu ser representado - dominando o processo e não sendo dominado, atuando e não apenas respondendo às perguntas do cineasta - foi essencial para a construção do filme. Ele não só aceitou a proposta do realizador como acrescentou às suas ideias toda a carga mística que determina o pensamento da população local e sem a qual seria impossível conhecer as pessoas que ainda habitam o Quartel de Indaiá.

Da mesma forma, a narrativa biográfica sobre Seu Pedro alcança uma forma de representação que leva em conta a fantasia e a constante reinvenção das lembranças e, consequentemente, do sujeito que conta suas memórias. O documentário parece não almejar a autenticidade tão buscada no gênero, mas sim alcançar um registro de toda a complexidade do ser humano no trabalho de recontar sua história. No filme de Rodrigo Siqueira "o verdadeiro [...] não se mantém como forma discursiva", pois cria-se um "regime de imagem que potencializa o falso [...] em que o homem verídico morre [...] Surge um falsário que produz o indiscernível para ver passar uma narração que está sempre se modificando". Seu Pedro de Alexina é o falsário, o homem que muda a narrativa fílmica e que possibilita que o documentarista habite "espaços incompossíveis, vários possíveis metamorfoseantes, e, assim, outras escritas cinematográficas". (Furtado, 2010: 232).

Nesta nova forma de prática documental o objeto central são os processos e não mais a imagem. Como afirma Furtado:

A imagem faz coincidir a experiência vital com a experiência estética. Um estado de arte documental de total ruptura e dissidência com o encadeamento do corpo totalizado da imagem. O que passa com o documentário quando se instala no modo de fazer cinema da obra de arte contemporânea é a sua inscrição no precário, em que a experiência na obra é central. (Furtado, 2010: 235).

Relacionando esta forma de fazer documentário com as teorias de Deleuze sobre o cinema trazidas por Roberto Machado, poderíamos concluir que Terra deu, terra come se enquadraria no tipo de imagem designado de imagem- 
tempo, onde há uma visão pura ou superior, "um exercício transcendental da faculdade de sentir que suspende o reconhecimento sensório-motor da coisa [...] proporcionando um conhecimento e uma ação revolucionária" (Machado, 2010: 273). Este cinema visionário, classificação na qual pode se enquadrar a obra em questão, transcende o sensório-motor e tende ao Todo do Tempo, como afirma Pelbart. Este Todo, segundo Deleuze, seria a Relação que não cessa de mudar, que não para de fazer-se e este Todo é concebido como Aberto, pois contém em si "a imensidão do passado e futuro" (Pelbart, 1998: 06). A imagem-tempo seria, então, o canal de acesso a este Todo, pois ela

[...] não se restringe ao presente em que aparece, que é apenas uma parte deste Todo e que permite representá-lo indiretamente. [...] coexiste com esse presente o passado que não é um antigo presente, e um futuro que não é um presente por vir. [...] Trata-se de fazer o antes e o depois entrarem na própria imagem presente, da qual de qualquer modo eles são inseparáveis no interior de um Todo coexistente, nos quais ele cai incessantemente. (Pelbart 1998: 13).

A imagem-tempo daria lugar a uma narração cristalina, a qual "deixa de ser verídica, de visar a verdade, de pretender ser verdadeira até mesmo na ficção, para se tornar falsificadora" (Machado, 2010: 282). Esta crítica à noção de verdade trazida por Deleuze a partir do pensamento de Nietzche, traz uma apologia da arte que é considerada como força vital. "O poder criador, transfigurador da arte, com sua perspectiva para além do bem e do mal e de verdade e aparência, é o grande estimulador da vida, a força capaz de se contrapor à negação da vida" (Machado, 2010: 284). Fugindo de estereótipos ligados à prática e à estética do gênero documentário, muitos filmes, assim como Terra deu, terra come, têm conseguido trazer à tona a velha e nunca concluída discussão a respeito dos limites da representação do real.

Ao questionar esse limite e embaçar a fronteira entre ficção e documentário a obra de Rodrigo Siqueira se enquadra como uma profanação do dispositivo cinema documentário e também uma profanação do próprio dispositivo festival, ao fazer um reuso das possibilidades fílmicas do gênero. O filme designa novas possibilidades de uso do documentário, desloca o lugar de uso convencional da narrativa ao se aproximar da ficcionalização, mas mantém intacta as forças em jogo dentro do gênero documental e dentro do dispositivo festival: realizadores, personagens, críticos, espectadores etc. (Agamben, 2007). Em outra perspectiva Terra deu, terra come exerce uma profanação lúdica que se aproximaria de uma trapaça, pois cria "um ambiente propício para uma subjetivação, capaz de permitir a esse sujeito interagir com a obra, retirando dela elementos que irão se transformar em componentes seus" (Baptista, 2015: 20). 


\section{Referências bibliográficas}

Agamben, G. (2009). O que é contemporâneo? E outros ensaios. Chapecó: Argos.

Agamben, G. (2007). Elogio da profanação. In G. Agamben, Profanações. São Paulo: Boitempo.

Aumont, J. (2004). O olho interminável: cinema e pintura. Rio de Janeiro: Cosac \& Naify.

Aumont, J. (1993). A imagem. Campinas: Papirus.

Baptista, M.R. (2015). A profanação dos dispositivos em Giorgio Agamben. Revista Estação Literária, 13: 10-23. Londrina. Disponível em http://www.uel.br/pos/letras/EL/vagao/EL13-Art1.pdf

Bernardet, J.-C. (2003). Cineastas e imagens do povo. São Paulo: Companhia das Letras.

Cunha, M.T. (2007). Do baú ao arquivo: escritas de si, escritas do outro. Patrimônio e Memória, 3(1): 45-62. São Paulo: Unesp. Disponível em http://pem.assis.unesp.br/index.php/pem/article/view/8/455

Da-Rin, S. (2004). Espelho partido: tradição e transformação do documentário. Rio de Janeiro: Azougue Editorial.

Deleuze, G. (1996). O mistério de Ariana. Lisboa: Ed. Veja - Passagens.

Didi-Huberman, G. (1998). O que vemos, o que nos olha. São Paulo: Editora 34.

Ferro, M. (1988). O filme: uma contra análise da sociedade?. In J. Le Goff \& P. Nora (Org.), História: novos objetos, vol. 3. Rio de Janeiro: Livraria Francisco Alves.

Foucault, M. (2000). Microfísica do poder. Rio de Janeiro: Graal.

Frayze-Pereira, J.A. (2005). Arte, dor: inquietudes entre estética e psicanálise. São Paulo: Ateliê Editorial.

Freire, M. (2009). A estética contra a ética: sobre os limites da representação do outro na produção audiovisual contemporânea. In B. Furtado (Org.), Imagem contemporânea: cinema, tv, documentário, fotografia, videoarte, games..., vol. 1, São Paulo: Hedra.

Furtado, B. (2009). O documentário como obra de arte. In B. Furtado (Org.), Imagem contemporânea: cinema, $t v$, documentário, fotografia, videoarte, games..., vol. 1. São Paulo: Hedra.

Galle, H.P.E. (2006). Elementos para uma nova abordagem da escritura autobiográfica. Matraga, 18: 64-91. Rio de Janeiro: UFRJ. 
Gaudreault, A. \& Jost, F. (2009). A narrativa cinematográfica. Brasília: Editora Universidade de Brasília.

Gauthier, G. (2011). O documentário: um outro cinema. Campinas: Papirus.

Guimarães, D.M. (1993). O vazio iluminado: o olhar dos olhares (CinemaPsicanálise). Rio de Janeiro: Notrya.

Joly, M. (1996). Introdução à análise da imagem. Campinas: Papirus.

Lacoue-Labarthe, P. (2000). A imitação dos modernos: ensaios sobre arte e filosofia. São Paulo: Paz e Terra.

Lima, H.E. (2007). Narrar, pensar o detalhe: à margem de um projeto de Carlo Ginzburg. ArtCultura, jul.-dez, 9(15): 99-111. Uberlândia: UFUpp.

Lins, C. (2008). Filmar o real. Rio de Janeiro: Jorge Zahar Editora.

Machado, R. (2010). Deleuze, a arte e a filosofia. Rio de Janeiro: Jorge Zahar.

Maia, K.F. (2011). Entre o real e a ficção: (r)evoluções éticas e estéticas do documentário. Semana do Audiovisual da Universidade Estadual de Goiás, 1, Goiânia, Anais... Goiânia: UEG.

Maia, K.F. (2014a). É Tudo Verdade (1996-2010): a evolução do documentarismo brasileiro e a consolidação do festival como dispositivo autorizador. Congresso de Ensino, Pesquisa e Extensão da Universidade Federal de Goiás, 11 (pp. 116-2118). Goiânia, Anais... Goiânia: UFG.

Maia, K.F. (2014b). O festival de cinema no Brasil: as primeiras iniciativas, o período Embrafilme e a gestão atual da Ancine. Seminário de Pesquisa da Pós-Graduação em História UFG/ PUC-GO, 7 (pp. 159-168). Goiânia. Anais... Goiânia: UFG/PUC-GO.

Maia, K.F. (2014c). O documentarista enquanto artista do cotidiano: a mimese, a genialidade e a relação com as imagens da realidade. Simpósio Nacional de História Cultural, 7. São Paulo, Anais... São Paulo: USP.

Malatian, T.M. (2008). A biografia e a história. Cadernos Cedem, 1(1): 16-31. São Paulo: Unesp.

Marcello, F.A. (2004). O conceito de dispositivo em Foucault: mídia e produção agonística de sujeitos maternos. Educação e Realidade, jan-jun, 29(1): 199-213. Porto Alegre.

Melo, C.T.V. (2002). O documentário como gênero audiovisual. Congresso Brasileiro de Ciências da Comunicação, 25. Salvador, Anais... Salvador.

Nichols, B. (2005). Introdução ao documentário. Campinas: Papirus.

Noronha, M.P. \& Maia, K.F. (2013). Memória, biografia e cinema: as três diferentes maneiras de dar voz ao outro. Simpósio Internacional de História, 6. Goiânia. Anais... Goiânia: UFG. 
Noronha, M.P. (2007). Interartes e dança: uma pequena história entre o háptico e a scinestesia. Engrupe Dança, Pesquisas Multidisciplinares em Dança, 1: 54-63.

Parente, A. (2007). Cinema em trânsito: do dispositivo do cinema ao cinema do dispositivo. In M. Penafria \& Í.M. Martins (Orgs.), Estéticas do digital: cinema e tecnologia. Covilhã: Livros Labcom. Disponível em: http://www.livroslabcom.ubi.pt/book/52

Pelbart, P.P. (1998). O tempo não reconciliado. São Paulo: Perspectiva.

Ricouer, P. (2010). A memória, a história e o esquecimento. Campinas: Unicamp.

Seligmann-Silva, M. (2005). Testemunho e a política da memória: o tempo depois das catástrofes. Projeto Historia, jun: 71-98. São Paulo: PUC-SP. Disponível em http://www.pucsp.br/projetohistoria/downloads/volume30 /04-Artg-(Marcio).pdf

Souza, E.C. (2008). (Auto) Biografia, identidade e alteridade: modos de narração, escritas de si e práticas de formação da pós-graduação. Dossiê Fórum, POSGRA/UFS, Ano 2, jul-dez, 4: 37-50. Sergipe: UFSpp. Disponível em http://200.17.141.110/periodicos/revista_forum_identidades/revis tas/ARQ_FORUM_IND_4/DOSSIE_FORUM_Pg_37_50.pdf

Teixeira, F.E. (2006). Documentário moderno. In F. Mascarelo (Org.). História do cinema mundial. Campinas: Papirus.

Vanoye, F. \& Goliot-Lété, A. (1994). Ensaio sobre a análise fílmica. Campinas: Papirus.

\section{Filmografia}

Terra deu, terra come (2009), de Rodrigo Siqueira. 